\title{
Biomarker monitoring for food contaminants
}

\author{
Hermann M. Bolt ${ }^{1}$
}

Received: 15 January 2018 / Accepted: 17 January 2018 / Published online: 6 February 2018

c) Springer-Verlag GmbH Germany, part of Springer Nature 2018

In this issue of the Archives of Toxicology, Ivonne Rietjens and colleagues contribute a comprehensive review about exposure assessment of food contaminants (Rietjens et al. 2018). The authors focus on five process-related compounds: acrylamide, monochloropropane-1,2-diols (MCPDs), glycidyl ethers, furan and acrolein. For each compound or compound group, occurrence, urinary, blood as well as tissue biomarkers, PBPK studies and possible endogenous formation of the respective biomarkers are summarized and discussed (Rietjens et al. 2018).

Accurate exposure estimation is a critical and particularly a challenging step in risk assessment. As soon as the relationship between blood, urine or tissue biomarkers and internal concentrations of the compound of interest has been understood, extrapolation to external exposure is possible. For this purpose, typically PBPK models (or reverse PBPK models) are used (Strikwold et al. 2017; Wang et al. 2017; Poon et al. 2017; Schenk et al. 2017; Al-Malahmeh et al. 2017). Besides their classical application, PBPK models can also be used for extrapolation between species (Ghallab 2015; Thiel et al. 2015) and for in vitro to in vivo extrapolation, if adequate in vitro systems are available (Frey et al. 2014; Stöber 2016; Leist et al. 2017).

One further step that can be built on the knowledge of compound concentrations in tissues are pharmacodynamic spatio-temporal models (Schliess et al. 2014; Bartl et al. 2015). With the help of such models, predictions of organ toxicity have been made for specific internal exposures (Ghallab et al. 2016). Although this modeling approach still represents a field of basic research, it nevertheless demonstrates the basic importance of internal biomarkers of exposure.

In conclusion, biomarker-based assessment of exposure is an important tool to evaluate exposure of consumers.

Hermann M. Bolt

bolt@ifado.de

1 IfADo-Leibniz Research Centre for Working Environment and Human Factors at TU Dortmund, Ardeystr. 67, 44139 Dortmund, Germany
The present review of Rietjens and colleagues is a must read for anyone interested in applied aspects of biomarker monitoring.

\section{References}

Al-Malahmeh AJ, Al-Ajlouni A, Wesseling S et al (2017) Physiologically based kinetic modeling of the bioactivation of myristicin. Arch Toxicol 91(2):713-734

Bartl M, Pfaff M, Ghallab A et al (2015) Optimality in the zonation of ammonia detoxification in rodent liver. Arch Toxicol 89(11):2069-2078

Frey O, Misun PM, Fluri DA et al (2014) Reconfigurable microfluidic hanging drop network for multi-tissue interaction and analysis. Nat Commun 30(5):4250

Ghallab A (2015) Interspecies extrapolation by physiologically based pharmacokinetic modeling. EXCLI J 14:1261-1263

Ghallab A, Cellière G, Henkel SG et al (2016) Model-guided identification of a therapeutic strategy to reduce hyperammonemia in liver diseases. J Hepatol 64(4):860-871

Leist M, Ghallab A, Graepel R et al (2017) Adverse outcome pathways: opportunities, limitations and open questions. Arch Toxicol 91(11):3477-3505

Poon KL, Wang X, Ng AS et al (2017) Humanizing the zebrafish liver shifts drug metabolic profiles and improves pharmacokinetics of CYP3A4 substrates. Arch Toxicol 91(3):1187-1197

Rietjens IMCM, Dussort P, Günther H et al. (2018) Exposure assessment of process-related contaminants in food by biomarker monitoring. Arch Toxicol. https://doi.org/10.1007/s00204-017-2143-2. ReviewArticle (epub ahead of print)

Schenk A, Ghallab A, Hofmann U et al (2017) Physiologically-based modelling in mice suggests an aggravated loss of clearance capacity after toxic liver damage. Sci Rep 7(1):6224

Schliess F, Hoehme S, Henkel SG et al (2014) Integrated metabolic spatial-temporal model for the prediction of ammonia detoxification during liver damage and regeneration. Hepatology 60(6):2040-2051. https://doi.org/10.1002/hep.27136

Stöber R (2016) Pathophysiology of cholestatic liver disease and its relevance for in vitro tests of hepatotoxicity. EXCLI J 15:870-871

Strikwold M, Spenkelink B, de Haan LHJ et al (2017) Integrating in vitro data and physiologically based kinetic (PBK) modelling to assess the in vivo potential developmental toxicity of a series of phenols. Arch Toxicol 91(5):2119-2133

Thiel C, Schneckener S, Krauss M et al (2015) A systematic evaluation of the use of physiologically based pharmacokinetic 
modeling for cross-species extrapolation. J Pharm Sci 104(1):191-206

Wang Q, Chen X, Ren Y et al (2017) Toxicokinetics and internal exposure of acrylamide: new insight into comprehensively profiling mercapturic acid metabolites as short-term biomarkers in rats and Chinese adolescents. Arch Toxicol 91(5):2107-2118 